\title{
Occupational stress and psychological health impact on hypertension of miners in noisy environment in Wulumuqi, China: a case-control study
}

Yaoqin Lu', ${ }^{1,2}$ Huan Yan ${ }^{3,4}$, Jiandong Yang ${ }^{5}$ and Jiwen Liu ${ }^{1 *}$

\begin{abstract}
Background: Hypertension has been declared as a global public health crisis by the World Health Organization, because of its high prevalence. It affects the health of one billion people worldwide and is directly responsible for the deaths of more than 10 million people per year. The purpose of our research was to explore the influence of occupational stress and psychological health on hypertension of miners who work in a noisy environment and provide decision reference for relevant departments to keep miners' health.
\end{abstract}

Methods: A case-control study was carried out in this research. The study subjects were divided into case groups and control groups based on whether they had hypertension or not. Effort-Reward Imbalance questionnaire and Self-Reporting Inventory questionnaire were used to investigate the psychological health status and occupational stress of the target population. General information was balanced between case and control groups through propensity score matching method. After propensity score matching, a multifactorial analysis was used to explore the impact of occupational stress and psychological health on hypertension.

Results: According to the result of the multivariate analysis, psychological health was hazard to hypertension ( $t=5.080$, $P<0.001)$ and occupational stress was not a direct risk factor for hypertension $(t=1.760, P=0.080)$. The model was statistically significant $\left(X^{2}=20.4, P<0.01\right)$.

Conclusions: For miners working in the noisy environment, psychological status was a direct risk factor to hypertension, while occupational stress was an indirect factor.

Keywords: Occupational stress, Psychological health, Hypertension, Miners, Noisy environment

\section{Background}

Hypertension has been declared as a global public health crisis by the World Health Organization, because it has high prevalence with affecting one billion people worldwide and being directly responsible for more than 10 million deaths per year [1-3]. Therefore, many scientists

\footnotetext{
* Correspondence: liujiwen@xjmu.edu.cn

'Department of Occupational and Environmental Health, College of Public Health, Xinjiang Medical University, Wulumuqi, Xinjiang, China

Full list of author information is available at the end of the article
}

have focused on hypertension studies with different directions. The research shows that the risk factors for hypertension include age, sex, lifestyles, obesity, immune and so on [4-8]. Recently, some researchers proposed that the environment has significant association with hypertension [9-11]. Meanwhile occupational stress and psychological health was proved to have influence on hypertension [12, 13]. Despite most of the research focused on the relationship between hypertension and noisy environment, noisy environment also inversely

(c) The Author(s). 2020 Open Access This article is licensed under a Creative Commons Attribution 4.0 International License, which permits use, sharing, adaptation, distribution and reproduction in any medium or format, as long as you give appropriate credit to the original author(s) and the source, provide a link to the Creative Commons licence, and indicate if changes were made. The images or other third party material in this article are included in the article's Creative Commons licence, unless indicated otherwise in a credit line to the material. If material is not included in the article's Creative Commons licence and your intended use is not permitted by statutory regulation or exceeds the permitted use, you will need to obtain permission directly from the copyright holder. To view a copy of this licence, visit http://creativecommons.org/licenses/by/4.0/ The Creative Commons Public Domain Dedication waiver (http://creativecommons.org/publicdomain/zero/1.0/) applies to the data made available in this article, unless otherwise stated in a credit line to the data. 
impacts occupational stress and psychological health $[14,15]$. Little is known about the relationship among occupational stress, psychological health and hypertension in occupational population who work in a noisy environment. The purpose of our research was to explore the influence of occupational stress and psychological health on hypertension in miners who work in a noisy environment and provide decision reference for relevant departments to keep miners' health.

\section{Methods}

\section{Study design}

The case-control study was adopted in this research. We measured sound level in workplace through the method of recommended by occupational health standards of the People's Republic of China (GBZ/T 189.8-2007). Noisy working environment was identified based on the criteria for defining noisy working environment. People who works in a noisy workplace were included in this study, and study population was identified through inclusion criteria and exclusion criteria. The study groups were divided into case groups and control groups based on whether miners having hypertension or not in Wulumuqi. Effort-Reward Imbalance questionnaire and SelfReporting Inventory questionnaire were used to investigate the psychological health status and occupational stress of the target population. General information was balanced between case and control groups by propensity score matching method (PSM). After propensity score matching between cases and control group, the multifactorial analysis was used to explore the impact of occupational stress and psychological health on hypertension. Structural equation method (SEM) was conducted to explore the risk factors of hypertension and for stable model selection. All participants signed the informed consent.

\section{Questionnaire design and content}

The international general questionnaire that Effort-Reward Imbalance and Self-Reporting Inventory was adopted in this research to investigate occupational stress and psychological health respectively. Electronic questionnaire was conducted to improve the efficiency of the questionnaire. The specific contents of the survey are as follows.

\section{General information investigation}

This section included general information, such as age, sex (Male or Female), ethnic (Han ethnic, Non-Han ethnic), educational level (Middle school, High school, Technological academy, Bachelor degree or above), working years, signed labor contract (Yes or No), professional title (No, Elementary, Middle and Senior),work shift (Day, Night and Shift work),working time per day (Less than or equal to $8 \mathrm{~h}$, More than $8 \mathrm{~h}$ ), working days per week (Less than or equal to 5 days, More than 5 days), marital status (Unmarried, Married, Dissociation, Bereft of one's spouse) and monthly income (Less than or equal to 3000 yuan,3000-5000yuan, 5000-7000yuan, More than 7000yuan) etc.

\section{Occupational stress investigation}

Chinese version of the Effort-Reward Imbalance Questionnaire adapted by Dr. Jian Li was to evaluate occupational stress. The questionnaire has 23 items belonging to three parts: External Effort (EE), Reward(R), and Overcommitment (OC). The part of EE has six items that are from item 1 to item 6 , the scores range from 6 to 30 , and scoring mode is positive integral. The part of $\mathrm{R}$ has eleven items that are from item 7 to item 17, the scores range from 11 to 55 , and scoring mode is negative integral. The part of $\mathrm{OC}$ has six items that are from item 18 to item 23, the scores range is 6 to 30, and scoring mode is positive integral. The answer to each of the 23 items has five levels, including Not, Basically not, Sometimes, Often and Always. Extrinsic effort-reward ratio (ERI ratio) was used to identify whether imbalance exists between extrinsic effort and reward. The ERI ratio is equal to the external effect score divided by the reward score and $C$, and $C$ is external effect items divided effect items. There is high input and low reward when ERI ratio greater than one, and non-high input and low reward when ERI ratio less than or equal to one [16-19].

\section{Psychological health investigation}

Self-Reporting Inventory is one of the best-known inventories for measuring psychological health state. There are 9 dimensions (including 90 items) in Self-Reporting Inventory, and the answer to each of the 90 items has five levels, including Not, Very light, Medium, Heavier and Serious. The 9 dimensions are somatization, obsessive-compulsive symptoms, interpersonal sensitivity, depression, anxiety, hostility, phobia, paranoid ideation and psychosis, and the scores range in these dimensions are from 12 to 60 , from 10 to 50 , from 9 to 45 , from 13 to 65 , from 10 to 50 , from 6 to 30 , from 7 to 35 , from 6 to 30 and from 10 to 50 respectively. In addition, the range of the total score for psychological health is from 90 to 450 . The scoring mode are positive integral for both the 9 dimensions and the total score of psychological health. The method of calculation for each index is as follows:(1) the total score is equal to the sum of the 90 items, (2) the total average score is equal to the total score divided by 90 , (3) the division of each dimension is equal to the sum of the individual dimensions divided by the number of items in each dimension, (4) number of positive items is the number of items with 
a total score great than or equal to 2, (5) number of negative items is the number of items with a single score of $1,(6)$ average score of positive symptoms is equal to the total score minus the number of negative items and divided by the number of positive items. When the total score is greater than 160 , and the number of positive items is greater than 43 or the score of any factor is greater than 2, then the result is positive, and further examination is required.

\section{Investigation methods}

Electronic questionnaire was conducted to improve the efficiency of the questionnaire. According to the Law of Prevention and Control of Occupational Diseases of the People's Republic of China, employers should establish and improve occupational health files and workers' health monitoring files. Therefore, we conducted questionnaires and blood pressure measurements to miners who work in a noisy workplace, when doctor conducted physical examination to them. Under the guidance of the investigators on-site, the miners who work in a noisy workplace registered into the electronic questionnaire interface through the scanned QR code by mobile phones, and filled out the questionnaire. The results can be collected by clicking on the "submit" button.

\section{Statistical methods and software}

Continuous variable was described by mean and standard deviation if continuous variable has normal distribution, otherwise median and quartile. Categorical variable was described by constituent ratio and ratio. T-test, ANOVA, rank test, structural equation model (SEM) and propensity score method (PSM) was used to explore risk factors for hypertension of miners in a noisy condition. In this study, all analyses were based on two-sided test and the test was considered as statistically significant when $P<0.05$. All the above processes were processed by $\mathrm{R}$ (Version 4.0.2).

\section{Quality control}

Investigators who were trained and passed the examination can carry out the investigations. In order to improve the completeness of the questionnaire, each item in the electronic questionnaire was required to be answered. If questionnaire of the respondents was incomplete, the questionnaire was not used. The validity analysis of the data was completed by senior data analyst.

\section{Criteria}

The criteria were set for obtaining more reliable results, including inclusion criteria, exclusion criteria, hypertension diagnostic criteria and criteria for defining noise working environment. The detailed content of these criteria are as follows.

\section{Criteria for defining a Noisy working environment}

Noise was measured in the workplace according to measurement method of occupational health standards of the People's Republic of China (GBZ/T 189.8-2007). Meanwhile, according to part 2 (physical agents) of occupational exposure limits for hazardous agents in the workplace in occupational health standards of the People's Republic of China (GBZ 2.2-2007), noise was defined in workplace environment. The detailed content of the criteria are as follows:

Miners exposed to an equivalent noise level of more than $85 \mathrm{~dB}(\mathrm{~A})$ for $8 \mathrm{~h}$ per day and 5 days per week were eligible for the study.

\section{Hypertension diagnostic criteria}

According to the Guidelines for Prevention and Treatment of Hypertension in China (2018), hypertension was diagnosed when the systolic blood pressure was greater than or equal to $140 \mathrm{mmHg}$ and the diastolic blood pressure was greater than or equal to $90 \mathrm{mmHg}$. Moreover, participants were asked to sit for at least $10 \mathrm{~min}$ before measurement. The right upper arm blood pressure was measured twice by Omron calibrated electronic sphygmomanometer for each subject, and result was reported as the average of the two measurements.

\section{Inclusion criteria and exclusion criteria}

All workers who work in the noisy workplace were incorporated into the study. The exclusion criteria were (1) those who had serious illness (except hypertension), (2) those who did not agree to participate in the investigation, (3) the questionnaire was invalid.

\section{Results}

\section{Sample collection}

There were 3785 miners who work in a noisy workplace in Wulumuqi. However, 47 miners among the 3785 miners disagreed to participate the survey and 93 miners had serious illness (except hypertension). Therefore, after excluding the miners who disagreed to participate and who were seriously sick, we issued a total of 3645 questionnaires to miners $\mathrm{e}$, and the participation rate was $96.30 \%$ (3645/3785). Finally, we collected 3645 questionnaires, and of which 3498 were valid questionnaires. Response rate and complete response rate was $100 \%$ $(3645 / 3645)$ and $95.97 \% \quad(3498 / 3645)$ respectively (Fig. 1).

\section{Demographic characteristics of the population}

Tables 1 and 2 shows the demographic characteristics of the case $($ Hypertension $=$ Yes $)$ and the control group 


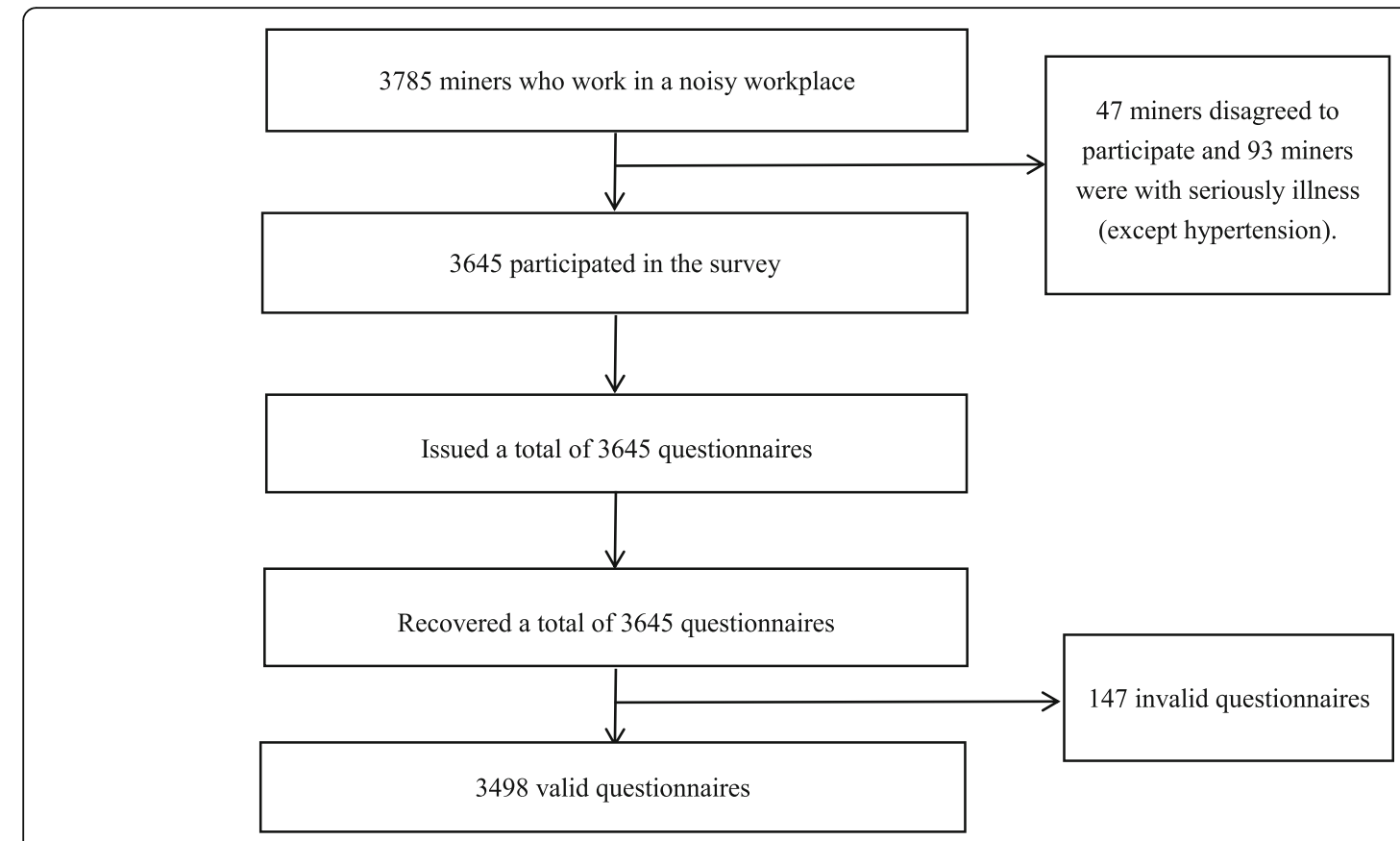

Fig. 1 Flowchart of sample collection

$($ Hypertension $=\mathrm{No})$. The median of age was 44 and 48 years old, and the median of working years was 24 and 29 years in the case and the control group respectively. Among the 3498 miners, 2484 were men (71.01\%) and 1014 were women $(28.99 \%)$. The number of miners with occupational stress was high in both the case and control group, but there was more psychological health problem in the case group than the control group. In addition, the distribution of professional title, work shift, marital status and monthly income was generally consistent in both groups.

\section{Confounding factor analysis}

To control the confounding factors and eliminate the bias of general demographic characteristics, the propensity score method (PSM) was used to select a total of 12 factors as the matching covariates, including age, sex, ethnic, educational level, working years, signed labor contract or not, professional title, work shift, working time per day, working days per week, marital status and monthly income. The caliper value and random seed were set at 0.02 and 1 respectively and 1:1 proximity

Table 1 Description of continuous variables

\begin{tabular}{llllll}
\hline & \multicolumn{2}{l}{ Hypertension = No } & & \multicolumn{2}{c}{ Hypertension $=$ Yes } \\
\cline { 2 - 3 } & $\boldsymbol{N}$ & $\boldsymbol{M}\left(\mathbf{Q}_{\mathbf{2 5}}, \mathbf{Q}_{\mathbf{7 5}}\right)$ & & $\boldsymbol{N}$ & $\boldsymbol{M}\left(\mathbf{Q}_{\mathbf{2 5}}, \mathbf{Q}_{\mathbf{7 5}}\right)$ \\
\hline Age & 2618 & $44(34,49)$ & & 880 & $48(45,51)$ \\
Working years & 2618 & $24(10,29)$ & & 880 & $29(24,32)$ \\
\hline
\end{tabular}

matching method was used. Hypertension and general demographic characteristics were defined as the dependent variable and independent variables respectively. Multiple logistic regression analysis was conducted to explore the efficiency of PSM. Before matching, there were statistically significant differences in age, sex, working years $(P<0.001)$. After matching, there were no statistically significant differences among characteristics of participants between the case group and the control group $(P>0.05)$ (Table 3$)$.

\section{Analysis of influencing factors}

After balancing the general information between case and control group, we used a multi factorial analysis to explore the impact of occupational stress and psychological health on hypertension. The model was statistically significant $\left(\chi_{2}=20.4, P<0.01\right)$. According to the result of the multivariate analysis, psychological health is hazards to hypertension $(t=5.080, P<0.001)$. However, the occupational stress was not significantly associated with hypertension $(t=1.760, P=0.080)$. (Table 4$)$.

Structural equation method was then conducted to explore the influencing factors for hypertension and for stable model selection. The criteria for a stable model are shown in Table 5 . The stable SEM model was selected by variables selection, model fitting and model validation. The model adjustment parameter is as in Table 6.

The final model path diagram is shown in Fig. 2. It can be seen that the influence of stress on hypertension 
Table 2 General information of categorical data

\begin{tabular}{|c|c|c|c|c|c|c|}
\hline & \multicolumn{2}{|c|}{ Hypertension = No } & \multicolumn{2}{|c|}{ Hypertension = Yes } & \multicolumn{2}{|l|}{ Total } \\
\hline & $\begin{array}{l}\text { Numbers } \\
(N)\end{array}$ & $\begin{array}{l}\text { Constituent } \\
\text { Ratio (\%) }\end{array}$ & $\begin{array}{l}\text { Numbers } \\
(N)\end{array}$ & $\begin{array}{l}\text { Constituent } \\
\text { Ratio (\%) }\end{array}$ & $\begin{array}{l}\text { Numbers } \\
\text { (N) }\end{array}$ & $\begin{array}{l}\text { Constituent } \\
\text { Ratio (\%) }\end{array}$ \\
\hline \multicolumn{7}{|l|}{ Sex } \\
\hline Male & 1678 & 64.09 & 806 & 91.59 & 2484 & 71.01 \\
\hline Female & 940 & 35.91 & 74 & 8.41 & 1014 & 28.99 \\
\hline \multicolumn{7}{|l|}{ Ethnic } \\
\hline Han ethnic & 2179 & 83.23 & 768 & 87.27 & 2947 & 84.25 \\
\hline Non-Han ethnic & 439 & 16.77 & 112 & 12.73 & 551 & 15.75 \\
\hline \multicolumn{7}{|l|}{ Educational level } \\
\hline Middle school & 109 & 4.16 & 38 & 4.32 & 147 & 4.20 \\
\hline High school & 496 & 18.95 & 287 & 32.61 & 783 & 22.38 \\
\hline Technological academy & 1215 & 46.41 & 389 & 44.20 & 1604 & 45.85 \\
\hline Bachelor degree or above & 798 & 30.48 & 166 & 18.86 & 964 & 27.56 \\
\hline \multicolumn{7}{|l|}{ Sign labor contract } \\
\hline Yes & 2596 & 99.16 & 879 & 99.89 & 3475 & 99.34 \\
\hline No & 22 & 0.84 & 1 & 0.11 & 23 & 0.66 \\
\hline \multicolumn{7}{|l|}{ Professional title } \\
\hline No & 974 & 37.20 & 341 & 38.75 & 1315 & 37.59 \\
\hline Elementary & 524 & 20.02 & 97 & 11.02 & 621 & 17.75 \\
\hline Middle & 634 & 24.22 & 230 & 26.14 & 864 & 24.70 \\
\hline Senior & 486 & 18.56 & 212 & 24.09 & 698 & 19.95 \\
\hline \multicolumn{7}{|l|}{ Work shift } \\
\hline Day & 1310 & 50.04 & 457 & 51.93 & 1767 & 50.51 \\
\hline Night & 83 & 3.17 & 26 & 2.95 & 109 & 3.12 \\
\hline Shift work & 1225 & 46.79 & 397 & 45.11 & 1622 & 46.37 \\
\hline \multicolumn{7}{|l|}{ Working time per day } \\
\hline$\leq 8$ & 1830 & 69.90 & 631 & 71.70 & 2461 & 70.35 \\
\hline$>8$ & 788 & 30.10 & 249 & 28.30 & 1037 & 29.65 \\
\hline \multicolumn{7}{|l|}{ Working days per week } \\
\hline$\leq 5$ & 1970 & 75.25 & 641 & 72.84 & 2611 & 74.64 \\
\hline$>5$ & 648 & 24.75 & 239 & 27.16 & 887 & 25.36 \\
\hline \multicolumn{7}{|l|}{ Marital status } \\
\hline Unmarried & 282 & 10.77 & 42 & 4.77 & 324 & 9.26 \\
\hline Married & 2160 & 82.51 & 765 & 86.93 & 2925 & 83.62 \\
\hline Dissociation & 162 & 6.19 & 65 & 7.39 & 227 & 6.49 \\
\hline Bereft of one's spouse & 14 & 0.53 & 8 & 0.91 & 22 & 0.63 \\
\hline \multicolumn{7}{|l|}{ Monthly income } \\
\hline$\leq 3000$ Yuan & 708 & 27.04 & 254 & 28.86 & 962 & 27.50 \\
\hline $3000 \sim 5000$ Yuan & 1476 & 56.38 & 509 & 57.84 & 1985 & 56.75 \\
\hline $5000 \sim 7000$ Yuan & 377 & 14.40 & 102 & 11.59 & 479 & 13.69 \\
\hline >7000 Yuan & 57 & 2.18 & 15 & 1.70 & 72 & 2.06 \\
\hline \multicolumn{7}{|l|}{ Occupational Stress } \\
\hline No & 1279 & 48.85 & 359 & 40.80 & 1638 & 46.83 \\
\hline Yes & 1339 & 51.15 & 521 & 59.20 & 1860 & 53.17 \\
\hline \multicolumn{7}{|l|}{ Psychological health problem } \\
\hline No & 1527 & 58.33 & 355 & 40.34 & 1882 & 53.80 \\
\hline Yes & 1091 & 41.67 & 525 & 59.66 & 1616 & 46.20 \\
\hline
\end{tabular}


Table 3 Analysis of propensity score

\begin{tabular}{|c|c|c|c|c|c|}
\hline Factor & $\beta(C 195 \%)$ & OR (C195\%) & $t$ & $P$ & VIF \\
\hline \multicolumn{6}{|l|}{ Before } \\
\hline Intercept & $0.61(-1.69,2.90)$ & $1.84(0.18,18.26)$ & 0.520 & 0.610 & - \\
\hline Age & $0.02(0.01,0.04)$ & $1.02(1.01,1.04)$ & 2.870 & $<0.001$ & 2.450 \\
\hline Sex & $-1.64(-1.90,-1.38)$ & $0.19(0.15,0.25)$ & -12.360 & $<0.001$ & 1.050 \\
\hline Ethnic & $-0.15(-0.39,0.09)$ & $0.86(0.68,1.10)$ & -1.190 & 0.230 & 1.030 \\
\hline Educational level & $-0.03(-0.14,0.09)$ & $0.97(0.87,1.09)$ & -0.480 & 0.630 & 1.270 \\
\hline Working years & $0.03(0.02,0.05)$ & $1.03(1.02,1.05)$ & 5.150 & $<0.001$ & 2.550 \\
\hline Sign labor contract & $-1.62(-3.70,0.45)$ & $0.20(0.02,1.58)$ & -1.530 & 0.130 & 1.000 \\
\hline Professional title & $-0.02(-0.09,0.05)$ & $0.98(0.92,1.05)$ & -0.560 & 0.580 & 1.040 \\
\hline Work shift & $0.07(-0.03,0.16)$ & $1.07(0.97,1.17)$ & 1.410 & 0.160 & 1.230 \\
\hline Working time per day & $0.05(-0.15,0.24)$ & $1.05(0.86,1.27)$ & 0.460 & 0.640 & 1.160 \\
\hline Working days per week & $0.05(-0.14,0.24)$ & $1.05(0.87,1.27)$ & 0.510 & 0.610 & 1.030 \\
\hline Marital status & $0.18(-0.04,0.40)$ & $1.20(0.96,1.49)$ & 1.630 & 0.100 & 1.090 \\
\hline Monthly income & $-0.09(-0.22,0.03)$ & $0.91(0.80,1.03)$ & -1.460 & 0.140 & 1.160 \\
\hline \multicolumn{6}{|l|}{ After } \\
\hline Intercept & $-13.26(-649.75,623.23)$ & $0.00(0.00,4.6 e+270)$ & -0.040 & 0.970 & - \\
\hline Age & $0.02(0.00,0.04)$ & $1.02(1.00,1.05)$ & 2.190 & 0.030 & 2.770 \\
\hline Sex & $0.12(-0.24,0.47)$ & $1.13(0.79,1.60)$ & 0.650 & 0.520 & 1.050 \\
\hline Ethnic & $-0.01(-0.29,0.28)$ & $0.99(0.75,1.32)$ & -0.050 & 0.960 & 1.020 \\
\hline Educational level & $0.01(-0.12,0.14)$ & $1.01(0.89,1.15)$ & 0.130 & 0.900 & 1.260 \\
\hline Working years & $-0.01(-0.03,0.01)$ & $0.99(0.97,1.01)$ & -1.100 & 0.270 & 2.780 \\
\hline Sign labor contract & $12.6(-623.89,649.08)$ & $296,558.57(0.00,7.83 e+281)$ & 0.040 & 0.970 & 1.000 \\
\hline Professional title & $0.00(-0.08,0.08)$ & $1.00(0.93,1.08)$ & 0.080 & 0.940 & 1.030 \\
\hline Work shift & $0.04(-0.06,0.15)$ & $1.04(0.94,1.16)$ & 0.800 & 0.420 & 1.220 \\
\hline Working time per day & $0.02(-0.21,0.24)$ & $1.02(0.81,1.27)$ & 0.140 & 0.890 & 1.150 \\
\hline Working days per week & $0.01(-0.21,0.23)$ & $1.01(0.81,1.25)$ & 0.090 & 0.930 & 1.030 \\
\hline Marital status & $-0.23(-0.47,0.02)$ & $0.79(0.62,1.02)$ & -1.810 & 0.070 & 1.050 \\
\hline Monthly income & $0.02(-0.13,0.16)$ & $1.02(0.88,1.18)$ & 0.220 & 0.820 & 1.110 \\
\hline
\end{tabular}

was through psychological health. In other words, stress has no direct influence on hypertension. In addition, according to the path diagram, psychological health, working years, sex and age show direct influence on hypertension. At the same time, sex and age also show indirect influence on stress. Moreover, educational and income have only one unidirectional pathway to influence hypertension, which indirectly affects hypertension through stress.

With regard to the statistical test, each path in the path diagram shows statistical significance $(P<0.05)$ (Table 7$)$.

\section{Discussion}

In this study, we investigated 3785 miners whose work exposed to a noisy environment in Wulumuqi. Cluster sampling is used in the study. The results discovered the relationship among occupational stress, psychological health and hypertension in miners whose work exposed to a noisy environment in Wulumuqi.

The study found that the demographic characteristics of the population, except sex, occupational stress and psychological health, was not significantly different

Table 4 Effects of psychological and occupational stress on hypertension

\begin{tabular}{llllll}
\hline Factor & $\boldsymbol{\beta}(\mathbf{C I 9 5 \% )}$ & $\boldsymbol{O R}(\mathbf{C I 9 5 \% )}$ & $\boldsymbol{t}$ & $\boldsymbol{P}$ & \multicolumn{1}{c}{ VIF } \\
\hline Intercept & $-0.37(-0.53,-0.21)$ & $0.69(0.59,0.81)$ & -4.470 & - \\
Psychological health & $0.51(0.31,0.71)$ & $1.67(1.37,2.03)$ & 5.080 & $<0.001$ & 1.070 \\
Occupational Stress & $0.18(-0.02,0.38)$ & $1.2(0.98,1.46)$ & 1.760 & 0.080 & 1.070 \\
\hline
\end{tabular}


Table 5 Criteria for a stable SEM model

\begin{tabular}{lll}
\hline Index & Recommend value & Acceptance \\
\hline$X^{2} / \mathrm{df}$ & $<3$ good fit $<5$ reasonable fit & Good \\
RMSEA & $<0.05$ good fit $<0.10$ reasonable fit & Reasonable \\
$\mathrm{NFI}$ & Above 0.9 & Good \\
$\mathrm{NNFI}$ & Above 0.9 & Good \\
$\mathrm{CFI}$ & Above 0.9 & Good \\
IFI & Above 0.9 & Good \\
SRMR & $<0.05$ good fit $<0.10$ reasonable fit & Reasonable \\
\hline
\end{tabular}

between the case and control group. Similar to other hard-labor working environment, it is a common phenomenon that there are more male than female miners [20]. Level of occupational stress and psychological health was different between the case and control group, indicating that occupational stress, psychological health and hypertension were correlated [21, 22].

Propensity score matching (PSM) is a statistical matching technique that attempts to estimate the effect of a treatment and intervention by accounting for the covariates that predict the treatment effects. It attempts to reduce the bias due to confounding variables that could be found in estimating the treatment effect from simply comparing outcomes among groups that received the treatment versus those that did not [23]. This method can adjust covariates more objectively and scientifically and thereby get more intuitive conclusions.

We analyzed the influence of occupational stress and psychological health on hypertension after controlling other factors through propensity score matching. The result showed that psychological health was one of the risk factors for hypertension, which was consistent with the study reported by Tevie J's [24]. Psychological health induced hypertension may relate to the sympathetic nervous system. Jeanie Park's study showed that psychological activities can directly affect the brain to influence the body's catecholamine secretion, thereby affecting the sympathetic nerve excitability [25]. Sympathetic excitation is one of the main physiological causes of hypertension [26-28]. The results showed no direct relationship

Table 6 Comparison of models before and after correction

\begin{tabular}{lll}
\hline & Before adjustment & After adjustment \\
\hline RMR & 14.197 & 0.204 \\
$G F I$ & 0.792 & 0.990 \\
$A G F I$ & 0.464 & 0.969 \\
$I F I$ & 0.194 & 0.976 \\
$C F I$ & 0.192 & 0.976 \\
RMSEA & 0.306 & 0.057 \\
PCLOSE & 0.000 & 0.067 \\
\hline
\end{tabular}

between occupational stress and hypertension, after balancing other factors through propensity score matching. To our knowledge, this is the first study to show such a view compared to previous studies [29, 30].

Structural equation method was used to further explore the influence factors of hypertension. The results showed that occupational stress had an indirect effect on hypertension. Stress that can cause the body to produce a stress response was proved to be the main reason for hypertension [31-33]. Occupational stress is one type of stress. Therefore, occupational stress can cause the body to produce a stress response too. Some researchers believe that under stress the level of certain hormones in our body will increase. Some of these hormones will affect our psychological condition, including norepinephrine, adrenaline, adrenal cortex hormones, etc. $[34,35]$. Therefore, the impact of occupational stress on hypertension may be caused by changes in psychological state, which was caused by increased secretion of certain hormones in the body under stress. Research shows that noise is one of the causes of occupational stress $[36,37]$. Therefore, working in a noisy environment for a long time will lead to increased occupational pressure on workers, and these workers will be more prone to hypertension.

Through the analysis of the path map, we found that psychological condition, working years, sex and age of miners working in the noisy environment have direct influence on hypertension. The results are consistent with some previous studies [38, 39]. Interestingly, we found that age and gender have both direct or indirect effects on occupational stress or psychological health. This may be related to the stress and psychological tolerance of different age and gender groups. In addition, income and education was also found to affect occupational stress. Some researchers believe that the more educated, the less stressed [39]. At the same time, studies show that low income was also a risk factor for occupational stress [40-43]. Not in the same way as education and income, working years directly affects psychological status and leads to high blood pressure. Facing the problems of career development, family life, children's education, employment and marriage, as well as various events affecting work and life, psychological problems may occur accompanied [44-46].

In summary, case control design was adopted in this study to explore the influence of occupational stress and psychological health on hypertension in miners whose work is exposed in a noisy environment. Through propensity score matching method to minimize confounding bias and achieve comparable improvement, the factors influencing hypertension of miners in a noisy environment were scientifically investigated. However, retrospective studies have limitations in data quality because the results were relied on memory, therefore 


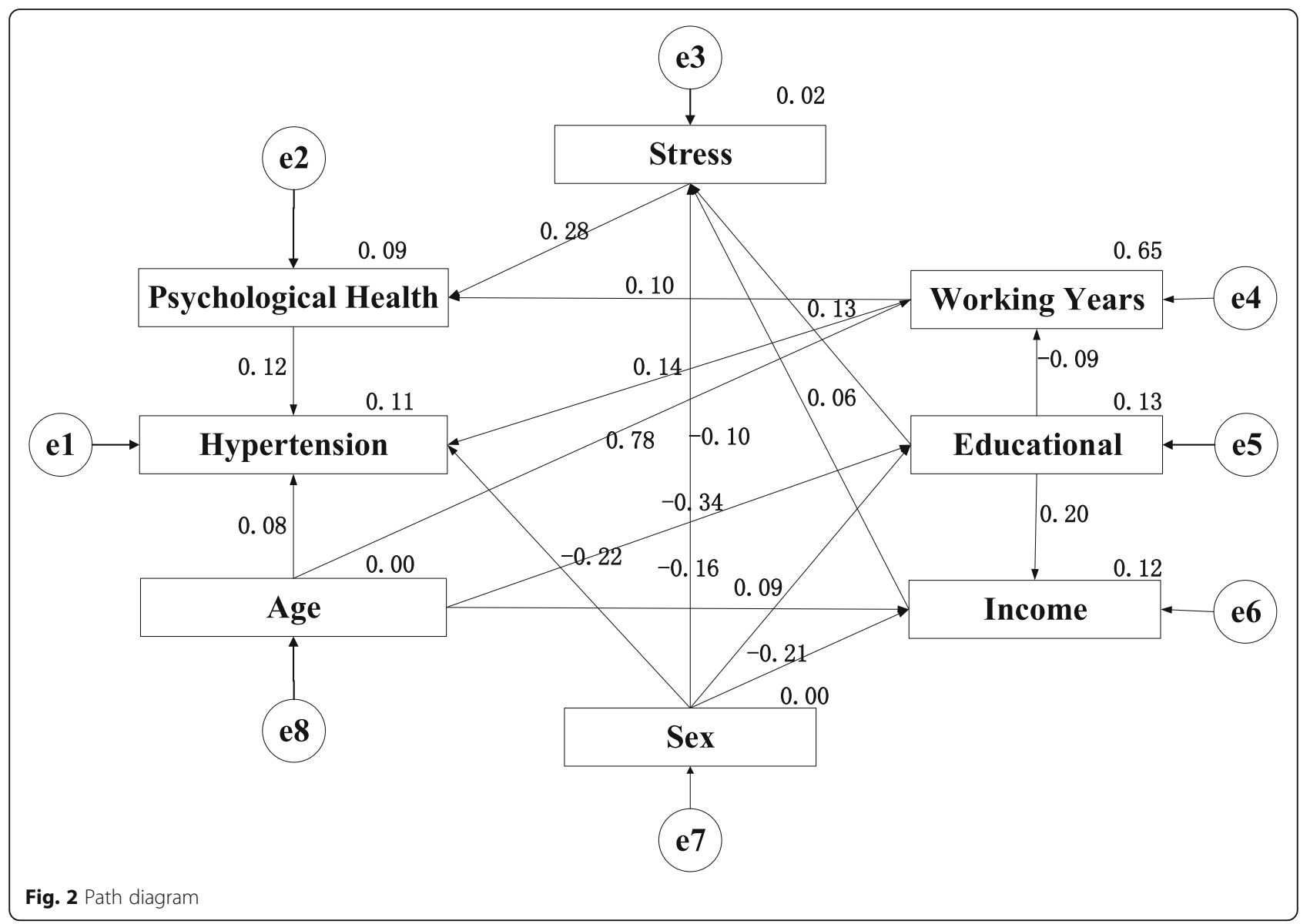

Table 7 Model parameter test

\begin{tabular}{|c|c|c|c|c|}
\hline Path & Standardized Estimate & S.E. & C.R. & $P$ \\
\hline Educational level $\leftarrow$ Sex & 0.093 & 0.029 & 5.784 & $<0.001$ \\
\hline Educational level $\leftarrow$ Age & -0.341 & 0.001 & -21.318 & $<0.001$ \\
\hline Monthly income $\leftarrow$ Age & -0.156 & 0.001 & -9.192 & $<0.001$ \\
\hline Monthly income $\leftarrow$ Educational level & 0.203 & 0.015 & 11.994 & $<0.001$ \\
\hline Monthly income $\leftarrow$ Sex & -0.211 & 0.025 & -13.131 & $<0.001$ \\
\hline Occupational Stress $\longleftarrow$ Sex & -0.101 & 0.019 & -5.830 & $<0.001$ \\
\hline Working Years $\leftarrow$ Age & 0.776 & 0.012 & 73.027 & $<0.001$ \\
\hline Working Years $\leftarrow$ Educational level & -0.086 & 0.143 & -8.147 & $<0.001$ \\
\hline Occupational Stress $\leftarrow$ Monthly income & -0.057 & 0.013 & -3.226 & 0.001 \\
\hline Occupational Stress $\longleftarrow$ Educational level & 0.134 & 0.011 & 7.673 & $<0.001$ \\
\hline Psychological health $\leftarrow$ Occupational Stress & 0.283 & 0.016 & 17.542 & $<0.001$ \\
\hline Psychological health $\leftarrow$ Working years & 0.102 & 0.001 & 6.334 & $<0.001$ \\
\hline Hypertension $\leftarrow$ Sex & -0.219 & 0.015 & -13.496 & $<0.001$ \\
\hline HypertensionŁWorking years & 0.141 & 0.001 & 5.213 & $<0.001$ \\
\hline Hypertension $\longleftarrow$ Psychological health & 0.124 & 0.014 & 7.763 & $<0.001$ \\
\hline Hypertension $\leftarrow$ Age & 0.081 & 0.001 & 3.025 & 0.002 \\
\hline
\end{tabular}


studies are treated in a low position in the hierarchy of evidence. To further verify the causality, prospective research needs to be conducted.

\section{Conclusion}

In a noisy working environment, the psychological condition of miners will directly affect the occurrence of hypertension. However, the impact of occupational stress on hypertension is achieved through affecting the psychological state.

\section{Abbreviations}

VIF: Variance Inflation Factor; ERI: Effort-Reward Imbalance; EE: External Effort; OC: Overcommitment; SEM: Structural Equation Model; ANOVA: Analysis of Variance; PSM: Propensity Score Method

\section{Acknowledgements}

The authors thank Dr. Xiaoli Zhang from Department of Biomedical Informatics at the Ohio State University for the critical review of the manuscript.

\section{Authors' contributions}

$Y L, H Y$ and $J Y$ conceived the idea. $Y L$ and $H Y$ conducted the investigation. $Y L, H Y$, JY and JL carried out the data curation. $Y L, H Y$ and $J Y$ analyzed data. $Y L$ and $J Y$ wrote the first draft. $Y L$ and $H Y$ were involved in writing, reviewing and editing. $Y L$ and $H Y$ contributed to the work equally and should be regarded as co-first authors. All authors read and approved the final manuscript.

\section{Funding}

This study was supported by the National Natural Science Foundation of China, grant number 81760581 and Public Health and Preventive Medicine, the 13th Five-Year Plan Key Subject of Xinjiang Uygur Autonomous Region. The funders had no role in the implementation of the study and in the decision to publish the study findings.

\section{Availability of data and materials}

The datasets used and/or analyzed during the current study are available from the corresponding author on reasonable request.

\section{Ethics approval and consent to participate}

The study protocol was approved by the Scientific and Research Committee of the Wulumuqi Center for Disease Control and Prevention Medical Research Council. All subjects signed an informed consent form, and the anonymity of personal information was guaranteed during data analysis.

\section{Consent for publication}

Not Applicable.

\section{Competing interests}

The authors declare no conflict of interest. The funders had no role in the design of the study; in the collection, analyses, or interpretation of data; in the writing of the manuscript, or in the decision to publish the results.

\footnotetext{
Author details

${ }^{1}$ Department of Occupational and Environmental Health, College of Public Health, Xinjiang Medical University, Wulumuqi, Xinjiang, China. ${ }^{2}$ Department of Science and Education, Wulumuqi Center for Disease Control and Prevention, Wulumuqi, Xinjiang, China. ${ }^{3}$ Department of Nutrition and Food Hygiene, College of Public Health, Xinjiang Medical University, Wulumuqi, Xinjiang, China. ${ }^{4}$ Xinjiang Engineering Technology Research Center for Green Processing of Nature Product Center, Xinjiang Autonomous Academy of Instrumental Analysis, Wulumuqi, Xinjiang, China. ${ }^{5}$ Department of Tuberculosis Control and Prevention, Wulumuqi Centre for Disease Control and Prevention, Wulumuqi, Xinjiang, China.
}

Received: 26 November 2019 Accepted: 25 October 2020

Published online: 10 November 2020

\section{References}

1. Forouzanfar MH, Afshin A, Alexander LT, et al. GBD 2015 risk factors collaborators. Global, regional, and national comparative risk assessment of 79 behavioral, environmental and occupational, and metabolic risks or clusters of risks, 1990-2015: a systematic analysis for the global burden of disease study 2015. Lancet. 2016;388:1659-724.

2. World Health Organization (WHO). A Global Brief on Hypertension: Silent Killer, Global Public Health Crisis [Online] [R]. Available from http://www. who.int.proxy1.cl.msu.edu/cardiovascular_diseases/publications/global_ brief_hypertension/en/. 2013.

3. Sinnott SJ, Smeeth L, Williamson E, et al. Trends for prevalence and incidence of resistant hypertension: population-based cohort study in the UK 1995-2015. BMJ. 2017;358:j3984.

4. Dzikowicz DJ, Carey MG. Obesity and hypertension contribute to prolong QRS complex duration among middle-aged adults. Ann Noninvasive Electrocardiol. 2019;29:e12665.

5. Drummond GR, Vinh A, Guzik TJ, et al. Immune mechanisms of hypertension. Nat Rev Immunol. 2019;19:517.

6. Díaz-Gutiérrez J, Ruiz-Estigarribia L, Bes-Rastrollo M, et al. The role of lifestyle behavior on the risk of hypertension in the SUN cohort: the hypertension preventive score. Prev Med. 2019;123:171-8.

7. Gao FL, Han T, Zhang W, et al. Relationship between blood pressure variability and severity of cerebral infarction, carotid intima-media thickness of acute cerebral infarction patients complicated with h-type hypertension. Pract J Cardiac Cerebral Perumal Vasc Dis. 2017;25(8):45-8.

8. Cui JZ, May H, Li HJ, et al. Associated factors for blood pressure variability and in a community-dwelling hypertensive population in Ningxia. Chin Gen Pract. 2018;21(28):3490-4.

9. Bruno RM, Di Pilla M, Ancona C, et al. Environmental Factors and Hypertension. Curr Pharm Des. 2017;23(22):3239-46.

10. Fu W, Wang C, Zou L, et al. Association between exposure to noise and risk of hypertension: a meta-analysis of observational epidemiological studies. J Hypertens. 2017;35(12):2358-66.

11. Tessier-Sherman B, Galusha D, Cantley LF, et al. Occupational noise exposure and risk of hypertension in an industrial workforce. Am J Ind Med. 2017;60(12):1031-8.

12. Tao $N, A n H, X u L$, et al. Effect of occupational stress on hypertension in desert oilfield workers. Wei Sheng Yan Jiu. 2019;48(1):76-81.

13. Lu XT. Study on five states personality and mental health status of hypertension patients. MA dissertation. Beijing: Beijing University; 2018.

14. Tzivian L, Winkler A, Dlugaj M, Schikowski, et al. Effect of long-term outdoor air pollution and noise on cognitive and psychological functions in adults. Int J Hyg Environ Health. 2015;218(1):1-11.

15. Burns KN, Sun K, Fobil JN, et al. Heart Rate, Stress, and Occupational Noise Exposure among Electronic Waste Recycling Workers. Int J Environ Res Public Health. 2016;13(1):140.

16. Siegrist J, Li J. Work stress and altered biomarkers: A synthesis of findings based on the effort-reward imbalance model. Int J Environ Res Public Health. 2017;14(11):1373.

17. Du Prel JB, Siegrist J, Borchart D. The role of leisure-time physical activity in the change of work-related stress (eri) over time. Int J Environ Res Public Health. 2019:16(23):4839.

18. De Araújo TM, Siegrist J, Moreno AB, et al. Effort-reward imbalance, overcommitment and depressive episodes at work: Evidence from the elsa-brasil cohort study. Int J Environ Res Public Health. 2019;16(17):3025.

19. Siegrist J. Effort-reward imbalance at work and cardiovascular diseases. Int J Occup Med Environ Health. 2010;23(3):279-85.

20. Wei XX. A study on the relationship between burnout and social support in frontline miners. MA dissertation. Taiyuan: Taiyuan University of Technology; 2015.

21. Palagini L, Bruno RM, Cheng $P$, et al. Relationship between insomnia symptoms, perceived stress and coping strategies in subjects with arterial hypertension: psychological factors may play a modulating role. Sleep Med. 2016;19:108-15.

22. Crusto CA, Barcelona de Mendoza V, Connell CM, et al. The Intergenerational Impact of Genetic and Psychological Factors on Blood Pressure Study (InterGEN): Design and methods for recruitment and psychological measures. Nurs Res. 2016;65(4):331-8. 
23. Rosenbaum PR, Rubin DB. The central role of the propensity score in observational studies for causal effects. Biometrika. 1983;70(1):41-55.

24. Tevie J, Shaya FT. Association between mental health and comorbid obesity and hypertension among children and adolescents in the US. Eur Child Adolesc Psychiatry. 2015;24(5):497-502.

25. Park J, Marvar PJ, Liao P, et al. Baroreflex dysfunction and augmented sympathetic nerve responses during mental stress in veterans with posttraumatic stress disorder. J Physiol. 2017;595(14):4893-908.

26. Nishi EE, Almeida VR, Amaral FG, et al. Melatonin attenuates renal sympathetic overactivity and reactive oxygen species in the brain in neurogenic hypertension. Hypertens Res. 2019:42:1683.

27. Schlaich MP. What we need to know about renal nerve ablation for treatment of hypertension and other states of sympathetic overactivity. Am J Physiol Renal Physiol. 2016;311(6):F1267-70.

28. Tromp TR, Mahesh D, Joles JA, et al. Direct recording of cardiac and renal sympathetic nerve activity shows differential control in Renovascular hypertension. Hypertension. 2018;71(6):1108-16.

29. Strizhakov LA, Babanov SA, Lebedeva MV, et al. Arterial hypertension at the workplace: risk factors and the population value. Ter Arkh. 2018;90(9):138-43.

30. Tao N, Ge H, Wu W, et al. Association of glucocorticoid receptor gene polymorphism and occupational stress with hypertension in desert petroleum workers in Xinjiang, China. BMC Med Genet. 2018;19(1):213.

31. Lee JH, Kimm S, Han JS, et al. Chasing as a model of psychogenic stress: characterization of physiological and behavioral responses. Stress. 2018; 21(4):323-32.

32. Lang JD, Taylor DC, Kasper BS. Stress, seizures, and epilepsy: patient narratives. Epilepsy Behav. 2018;80:163-72.

33. Black PH. Stress and the inflammatory response: a review of neurogenic inflammation. Brain Behav Immun. 2002;16(6):622-53.

34. Li XW. On the effects of hormones on psychological activities. Psychol Explor. 1987;7:72-6.

35. Weinstock $M$. The potential influence of maternal stress hormones on development and mental health of the offspring. Brain Behav Immun. 2005; 19(4):296-308

36. Tennessen JB, Parks SE, Langkilde TL. Anthropogenic noise and physiological stress in wildlife. Adv Exp Med Biol. 2016;875:1145-8.

37. Wang WJ. Investigation and research on the job burnout of traffic police in Chengdu [D]. University of Electronic Technology; 2014.

38. Xie F, Xie L, Li X, et al. Prevalence and risk factors of hypertension combined with diabetes in middle and elder population in Nan'an district of Chongqing. Zhonghua Liu Xing Bing Xue Za Zhi. 2019;40(6):666-9.

39. Mingjuan Z, Binghui L, Qiao $H$, et al. A study on incidence and influencing factors of hypertension in teaching staff in a university of Henan Province. Chin J Evid Based Cardiovasc Med. 2019:11(6):722-724+728.

40. Chen-ran WANG, Yang LI, Chun-ping WANG, et al. Relationship between occupational stress and somatization in preschool teachers. Occup and Health. 2018;34(21):2920-6.

41. Vancampfort D, Koyanagi A, Ward PB, et al. Perceived stress and its relationship with chronic Medical conditions and multimorbidity among 229,293 community-dwelling adults in 44 low- and middle-income countries. Am J Epidemiol. 2017;186(8):979-89.

42. Pabayo R, Fuller D, Goldstein RB, et al. Income inequality among American states and the conditional risk of post-traumatic stress disorder. Soc Psychiatry Psychiatr Epidemiol. 2017;52(9):1195-204.

43. Sternberg RM, Nápoles AM, Gregorich S, et al. Mentes Positivas en Acción: feasibility study of a Promotor-delivered cognitive behavioral stress management program for low-income Spanish-speaking Latinas. Health Equity. 2019;3(1):155-61.

44. Han $\mathrm{R}$, Lian $\mathrm{YL}$, Wang $\mathrm{L}$, et al. Research on the correlation between menta health and occupational stress in different age groups. China J Health Psychol. 2016:24(1):45-8.

45. Pan $\mathrm{CH}$. Discussion on psychological pressure of operating room nurses with low qualifications and corresponding measures. For all Health. 2014; 8(17):130-40.

46. Guan SZ, Zhao J, Wang L. The association study of people's mental health and job burnout with different length of service. J North Sichuan Med College. 2014;29(1):16-9.

\section{Publisher's Note}

Springer Nature remains neutral with regard to jurisdictional claims in published maps and institutional affiliations.

Ready to submit your research? Choose BMC and benefit from:

- fast, convenient online submission

- thorough peer review by experienced researchers in your field

- rapid publication on acceptance

- support for research data, including large and complex data types

- gold Open Access which fosters wider collaboration and increased citations

- maximum visibility for your research: over $100 \mathrm{M}$ website views per year

At $\mathrm{BMC}$, research is always in progress.

Learn more biomedcentral.com/submissions 